\title{
Premarital mental disorders and physical violence in marriage: cross-national study of married couples
}

\author{
E. Miller, J. Breslau, M. Petukhova, J. Fayyad, J. Greif Green, L. Kola, S. Seedat, D. J. Stein, \\ A. Tsang, M. C. Viana, L. H. Andrade, K. Demyttenaere, G. de Girolamo, J. M. Haro, C. Hu, \\ E. G. Karam, V. Kovess-Masfety, T. Tomov and R. C. Kessler
}

\section{Background}

Mental disorders may increase the risk of physical violence among married couples.

\section{Aims}

To estimate associations between premarital mental disorders and marital violence in a cross-national sample of married couples.

\section{Method}

A total of 1821 married couples (3642 individuals) from 11 countries were interviewed as part of the World Health Organization's World Mental Health Survey Initiative. Sixteen mental disorders with onset prior to marriage were examined as predictors of marital violence reported by either spouse.

\section{Results}

Any physical violence was reported by one or both spouses in $20 \%$ of couples, and was associated with husbands' externalising disorders $(\mathrm{OR}=1.7,95 \% \mathrm{Cl} 1.2-2.3)$. Overall, the population attributable risk for marital violence related to premarital mental disorders was estimated to be $17.2 \%$.

\section{Conclusions}

Husbands' externalising disorders had a modest but consistent association with marital violence across diverse countries. This finding has implications for the development of targeted interventions to reduce risk of marital violence.

\section{Declaration of interest}

R.C.K. has been a consultant for AstraZeneca, Analysis Group, Bristol-Myers Squibb, Cerner-Galt Associates, Eli Lilly, GlaxoSmithKline, HealthCore, Health Dialog, Integrated Benefits Institute, John Snow, Kaiser Permanente, Matria, Mensante, Merck, Ortho-McNeil Janssen Scientific Affairs, Pfizer, Primary Care Network, Research Triangle Institute, Sanofi-Aventis Groupe, Shire US, SRA International, Takeda Global Research and Development, Transcept

Pharmaceuticals and Wyeth-Ayerst; has served on advisory boards for Appliance Computing ॥, Eli Lilly, Mindsite, OrthoMcNeil Janssen Scientific Affairs, Plus One Health

Management and Wyeth-Ayerst; and has had research support for his epidemiological studies from Analysis Group Bristol-Myers Squibb, Eli Lilly, EPI-Q, GlaxoSmithKline, Johnson \& Johnson Pharmaceuticals, Ortho-McNeil Janssen Scientific Affairs, Pfizer, Sanofi-Aventis Group and Shire US
Mental disorders are associated with both perpetration of and victimisation by physical violence in marital relationships (marital violence). ${ }^{1}$ Although studies have generally been concerned with presumed mental health consequences of violence, ${ }^{2-4}$ a growing body of evidence suggests that physical violence perpetration and victimisation in marital relationships may be partly a consequence of pre-existing mental disorders. ${ }^{5-7}$ Longitudinal studies of violence perpetration in intimate relationships have found a higher prevalence of substance misuse, depression, conduct disorder and attention-deficit hyperactivity disorder (ADHD) prior to the start of the relationship than in the general population. $^{5,6,8,9}$ Similarly, in a few studies being the victim of violence is associated with a higher prevalence of mood and anxiety disorders. ${ }^{1,7,10}$ These studies tend to focus on single disorders such as conduct disorder or depression among smaller samples, and do not generally address the co-occurrence of multiple mental disorders.

We examined associations between premarital mental disorders and the occurrence of marital violence in a crossnational epidemiologic sample of married and cohabiting couples interviewed in the World Mental Health (WMH) surveys. Our study has four unique features. First, the sample consisted of couples, of which both members answered an identical set of questions about their own perpetration of and victimisation by physical violence in their current marriage or marriage-like relationship. To our knowledge this is the only population-based study which combines reports of violence from both members of spousal pairs, offering potentially more accurate prevalence estimates of marital violence compared with individual selfreports. Second, both members of each couple completed the same detailed assessment of mental disorders. These data allow for examination of whether spousal characteristics, including history of mental disorders, modify the associations of an individual's premarital mental disorders with risk of marital violence. Third, the psychiatric assessment covered a broad range of psychiatric disorders. Some associations of specific mental disorders with marital violence might have been overestimated in previous studies that did not include or adjust for co-occurring disorders. Understanding which particular mental disorders or class of disorders may be associated with vulnerability for physical violence victimisation and perpetration could inform clinical screening and safety assessments. Fourth, the study included representative samples from a diverse set of 11 high-, middleand low-income countries, providing an opportunity to examine whether associations between mental disorders and marital violence are unique to high-income countries, where the bulk of previous research on marital violence has been conducted. Although the prevalence of physical violence in marriages varies significantly around the globe, if mental disorders contribute to marital violence risk through similar pathways we would expect the association of marital violence with premarital mental disorders to be relatively consistent. Identifying whether the contribution of premarital mental disorders to marital violence, found in studies of Western countries, ${ }^{5,8}$ is similar across diverse 
countries including non-Western settings is important for guiding international efforts to prevent marital violence.

\section{Method}

Out of the $11 \mathrm{WMH}$ countries that included a couples sample in their country-specific survey, five were classified by the World Bank as high income (Belgium, France, Italy, Spain, USA), three as upper-middle income (Brazil, Bulgaria, Lebanon) and three as low or lower-middle income (China, Nigeria, India); the total sample size was $n=8766$ (Table 1). ${ }^{11}$ Surveys took place in multistage clustered area probability household samples representative of specific regions (Brazil, India, China) or the entire nation (the remaining countries). Respondents were interviewed face to face in their homes by trained lay interviewers, who explained the purposes of the survey and made it clear that participation was voluntary, that respondents could decide not to answer any questions and that responses would be treated as confidential. These recruitment and consent procedures were approved by local human subjects research and ethics committees monitoring the study in each country. A more detailed discussion of WMH training, quality control and survey implementation is presented elsewhere. ${ }^{12}$

A supplemental 'couples sample' was incorporated into the survey design for each of these countries in which full interviews were conducted with both the initial respondent and the respondent's current spouse or cohabiting partner. A total of 1821 heterosexual couples were interviewed. The vast majority of these couples (95\%) were married. The remaining couples reported that they were 'living with someone in a marriage-like relationship' but were not married (for simplicity, we hereinafter refer to all couples as 'married'). Given the highly sensitive nature of questions asked in the survey, a certificate of confidentiality was

Table 1 Sample characteristics categorised by World Bank income level ${ }^{\text {a }}$

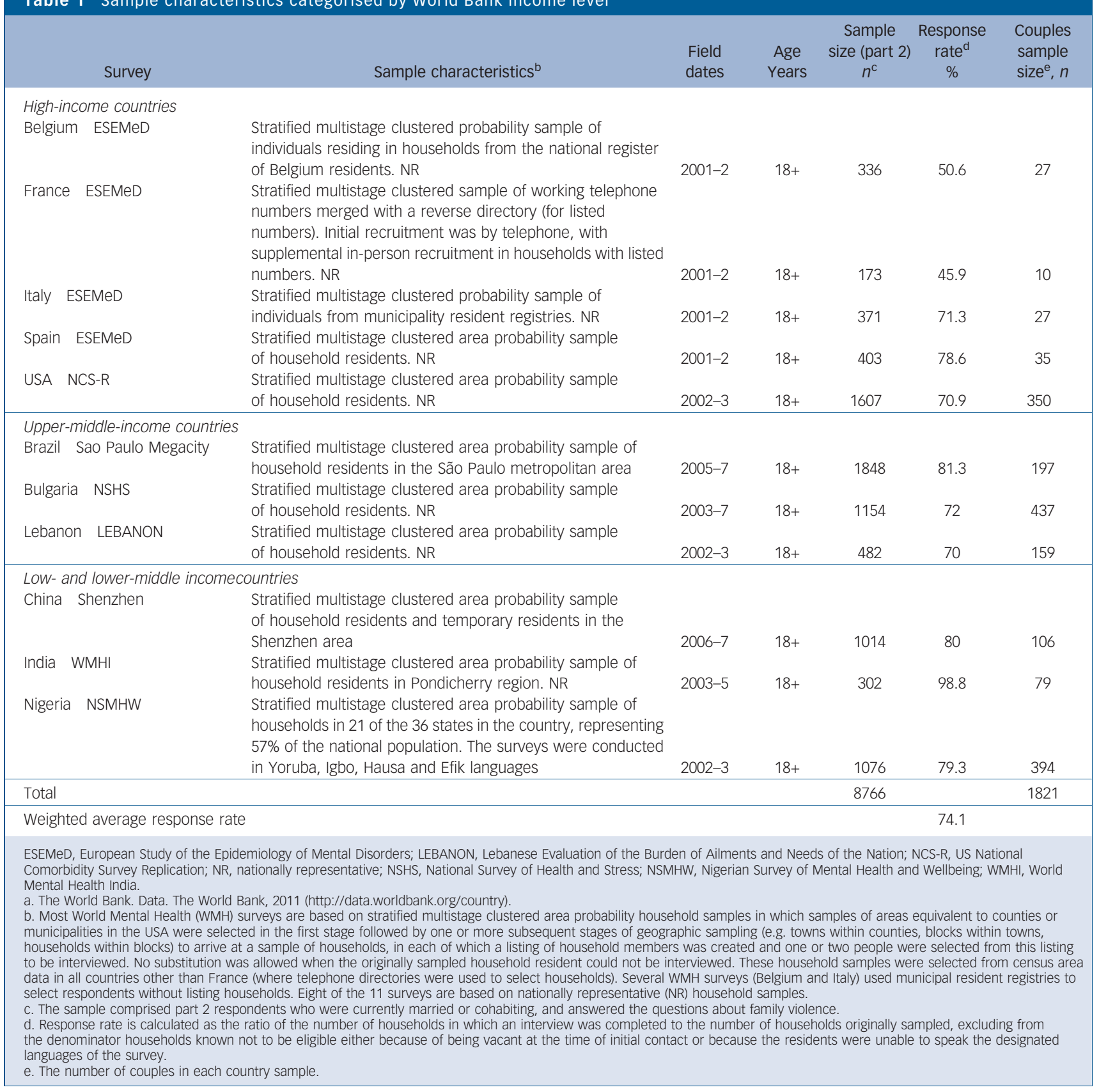


obtained to protect the data from subpoena, and every effort was made for interviews to be conducted in private. The proportion of interviews conducted when the respondent's spouse was present in the room for most of the interview varied by country, from $2.4 \%$ in China to $38 \%$ in India. Regardless of whether the spouse was present, in each case the respondents were presented with the list of violent behaviours in booklet form and asked whether they had ever experienced any of them. The spouse, if present, was asked not to look at the booklet or to sit behind the respondent. Interviewers were trained to assess for emotional distress following completion of the survey and to follow specific protocols for connecting participants to appropriate clinical services. In addition, owing to the length of the survey, its administration was extended over more than 1 day in some instances, as interviewers were trained to gauge respondent fatigue. Countryspecific response rates ranged from $45.9 \%$ (France) to $98.8 \%$ (India). The weighted (by sample size) average response rate was $74.1 \%$.

The interview was divided into two parts. Part 1 assessed core disorders and was completed by all respondents. Part 2 assessed additional disorders and numerous correlates, and was completed by $100 \%$ of respondents who met criteria for any part 1 disorder plus a probability subsample of other part 1 respondents. To reduce the possibility of recall bias, disorders defined as beginning in childhood (ADHD, conduct disorder, oppositional defiant disorder, separation anxiety disorder) were assessed only among respondents in the age range 18-44 years. The part 1 samples were weighted to adjust for differential probabilities of selection and residual discrepancies between sample and census on sociodemographic and geographic variables, to approximate population distributions in each country. The part 2 samples were additionally weighted to adjust for undersampling of part 1 respondents without part 1 disorders. A more detailed discussion of WMH sampling and weighting is presented elsewhere. ${ }^{12}$

\section{Diagnostic assessment}

Diagnoses were based on version 3.0 of the World Health Organization (WHO) Composite International Diagnostic Interview (CIDI) ${ }^{13}$ a fully structured lay-administered interview that generates diagnoses according to both ICD-10 and DSM-IV criteria (DSM-IV criteria were used here). Translation and backtranslation followed standard WHO procedures. ${ }^{14}$ The 16 lifetime diagnoses included ten internalising disorders: mood disorders (bipolar type $1 / 2$ or subthreshold disorder, major depressive episode, dysthymia) and anxiety disorders (agoraphobia with or without panic disorder, generalised anxiety disorder, panic disorder with or without agoraphobia, post-traumatic stress disorder, separation anxiety disorder, social phobia, specific phobia). The six externalising disorders included disruptive behaviour disorders (ADHD, conduct disorder, intermittent explosive disorder; oppositional defiant disorder) and substance use disorders (alcohol misuse with or without dependence, drug misuse with or without dependence). Masked clinical reappraisal interviews found good concordance between DSM-IV diagnoses based on the CIDI, ${ }^{15}$ and those based on the Structured Clinical Interview for DSM-IV. ${ }^{16,17}$ Organic exclusions but not diagnostic hierarchy rules were used in making diagnoses. The CIDI included retrospective disorder age-at-onset reports based on a specific question sequence that has been shown experimentally to improve recall accuracy. ${ }^{15}$ Premarital onset of mental disorders was defined as having a disorder with age at onset less than the age at which respondents reported starting to live with their current partner in a marriage-like relationship or marrying the current spouse (i.e. age at current marriage).

\section{Physical violence measures}

Physical violence in the respondent's current marriage was assessed using questions based on the modified Conflict Tactics Scale. ${ }^{18}$ Respondents were provided with a list of specific violent actions in written form in the respondent booklet and asked whether any of these actions ever occurred in the context of their current marital relationship. Physical violence was defined for respondents as 'pushed, grabbed or shoved, threw something, slapped or hit'. The question was phrased: 'People handle disagreements in many different ways. Over the course of your relationship, how often have you ever done any of these things on this list to your current spouse/partner - often, sometimes, rarely or never?' A report other than 'never', 'don't know' or 'refused' was coded as having ever experienced physical violence perpetration in the current marriage. Physical violence victimisation in the current marriage used the same examples, phrased as 'how often has your current spouse/partner done any of these things to you?' Answering positively to either the victimisation or perpetration items was coded as having experienced 'any' physical violence in current marriage; those responding positively to only perpetration or only victimisation items were coded as 'perpetration only' and 'victimisation only'; those responding they had both perpetrated violence and been victimised were coded as 'both perpetrator and victim'.

The terms 'intimate partner violence' and 'domestic violence' refer to a broad range of physical, sexual and emotional abuse among intimate partners (including dating relationships). In these analyses, 'any marital violence' refers specifically to physical violence in marital and marriage-like relationships as reported by either spouse/partner in the couple. Spouse reports of violence were added to respondents who reported no violence. For instance, if a respondent reported no violence, but their spouse reported perpetration, the respondent was coded as 'victim only'.

\section{Sociodemographic measures}

Additional demographic items included in analyses were age, age at start of current marriage or cohabiting relationship, years married or living together in current relationship and educational attainment.

\section{Statistical analysis}

Prevalence estimates for marital violence were calculated separately for men and women within each country (online Table DS1) and for all 11 countries together. In the couples sample, marital violence was considered present if reported by either member of a couple. Assortative mating by premarital psychiatric disorders was examined in logistic regression models in which the presence (prior to marriage) of any internalising or any externalising disorder in one spouse was examined as a predictor of the presence (prior to marriage) of disorder in the other spouse. Logistic regression models were used to estimate associations between premarital onset psychiatric disorders and violence in the current marriage. Sixteen internalising and externalising disorders were examined as predictors of marital violence. In a preliminary model building stage, the best-fitting model, using Akaike information criteria and Bayes information criteria, was one that included binary variables for presence of any internalising and any externalising disorder. Statistical adjustments were included for country, age at start of current marriage, age at start of marriage squared, years in the marriage and education (both husband's and wife's). These models were used in simulations to estimate population attributable risk proportions, i.e. the proportion of cases of marital violence attributable to mental disorders based on the assumption that the model represents 
Table 2 Prevalence of marital violence ever in current marriage as reported by either spouse in the 11 World Mental Health survey countries with couples samples

\begin{tabular}{|c|c|c|c|c|c|c|}
\hline \multirow[b]{2}{*}{ Violence report } & \multicolumn{2}{|c|}{ Women $(n=1821)$} & \multicolumn{2}{|c|}{ Men $(n=1821)$} & \multicolumn{2}{|c|}{ Total } \\
\hline & $n$ & Weighted \% (s.e.) & $n$ & Weighted \% (s.e.) & $n$ & Weighted \% (s.e.) \\
\hline Any marital violence & 404 & $19.8(1.1)$ & 404 & $20.2(1.1)$ & 808 & $20.0(0.9)$ \\
\hline Both perpetrator and victim & 174 & $8.1(0.7)$ & 171 & $8.1(0.7)$ & 345 & $8.1(0.6)$ \\
\hline Perpetrator only & 85 & $4.8(0.7)$ & 158 & $7.3(0.6)$ & 243 & $6.1(0.5)$ \\
\hline Victim only & 145 & $6.9(0.7)$ & 75 & $4.8(0.7)$ & 220 & $5.8(0.5)$ \\
\hline Total sample & 1821 & & 1821 & & 3642 & \\
\hline
\end{tabular}

causal relationships. In addition, to assess cross-national variations, the best-fitting model was re-run including interaction terms between country income level (dummy variables distinguishing high-, lower-middle- and low-income countries) and the measures of mental disorders in predicting marital violence. Country income level was used instead of separate dummy predictor variables for each country because of the small sample sizes in some surveys.

\section{Results}

\section{Prevalence of physical violence in current marriage}

In $80 \%$ of couples both spouses reported that there was no marital violence. For the majority of couples in which any violence was reported (65\%), violence was denied by one spouse. Reports of physical violence in the current marriage by either spouse are presented in Table 2. When discordant reports were adjusted by taking the response of the spouse who endorsed any marital violence as the true response, the prevalence in the couples sample with combined reports was $20.0 \%$ compared with the prevalence based on individual reports of $13.6 \%$ (comparison tables available from the authors on request). Among couples who reported marital violence, only 1 in 4 agreed on the spouses' respective roles in the violence, i.e. who had perpetrated it and who had been the victim. We therefore focused analyses on any marital violence as reported by either spouse.

\section{Premarital mental disorders and marital violence}

Table 3 shows associations between specific individual disorders and any marital violence, with separate models for men and women. Of 16 disorders, 10 had odds ratios greater than 1 for women, but only one - intermittent explosive disorder - was statistically significant. Similarly, for men, 11 of 16 disorders had odds ratio estimates greater than 1 , with only alcohol misuse (with or without dependence) reaching statistical significance. It is noteworthy that agoraphobia and dysthymia had significant negative associations with marital violence.

Given the high co-occurrence of mental disorders, multiple models were tested that included counts of the number of disorders and dummy variables for type of disorder. The bestfitting model included binary variables for any externalising or any internalising premarital mental disorder (Table 4). Statistical adjustments were included for age at start of current marriage, years in the marriage, education and country. When we examined predictors of any marital violence, odds ratios for externalising and internalising disorders were greater than 1 for both men and women, indicating higher risk of marital violence, but only one predictor reached statistical significance - premarital externalising disorders significantly predicted marital violence among men $(\mathrm{OR}=1.7,95 \%$ CI 1.2-2.3). Male premarital externalising disorders were significantly related to two subtypes of marital violence: cases where both spouses were perpetrators $(\mathrm{OR}=1.9,95 \% \mathrm{CI} 1.2-3.1)$ and cases where only the man was the perpetrator $(\mathrm{OR}=2.2,95 \%$ CI 1.4-3.5). Female premarital internalising disorders were significantly related to being in a relationship in which both spouses were perpetrators of violence $(\mathrm{OR}=1.6,95 \%$ CI 1.0-2.4).

\section{Spousal concordance for premarital mental disorders}

Premarital mental disorders may also be associated with marital violence because of spousal selection. For instance, an association between women's internalising disorders and marital violence might arise from a tendency for women with internalising disorders to marry men with externalising disorders, even in the absence of a direct effect of internalising disorders on marital violence. To investigate this possibility, logistic regression models were specified in the couples sample to estimate associations between husbands' and wives' premarital internalising and externalising disorders, with statistical controls for number of years in the relationship, country, education and age at start of the relationship. Results demonstrated homotypic assortment for both internalising and externalising disorders: women with internalising disorders were more likely to be married to men with internalising disorders $(\mathrm{OR}=1.5,95 \% \mathrm{CI} 1.1-2.2)$ and women

Table 3 Disorders predicting any marital violence in couples sample: separate models for men and women

$$
\text { Women }
$$
Odds ratio $(95 \% \mathrm{Cl}) \quad$ Odds ratio $(95 \% \mathrm{Cl})$

\begin{tabular}{|lll|}
\hline ADHD & $1.3(0.7-2.3)$ & $0.6(0.4-1.1)$ \\
\hline Agoraphobia & $0.9(0.4-2.1)$ & $0.2(0.0-1.0)^{*}$ \\
\hline Alcohol misuse & $0.7(0.3-1.6)$ & $2.0(1.4-3.0)^{*}$ \\
\hline Bipolar disorder & $2.1(0.9-4.8)$ & $1.3(0.6-2.6)$ \\
\hline Conduct disorder & $1.2(0.6-2.3)$ & $1.3(0.8-2.4)$ \\
\hline Drug misuse & $2.4(0.7-8.7)$ & $0.8(0.5-1.3)$ \\
\hline Dysthymia & $1.1(0.7-1.7)$ & $0.4(0.1-1.0)^{*}$ \\
\hline GAD & $1.1(0.6-1.7)$ & $1.1(0.4-3.1)$ \\
\hline IED & $1.4(1.0-2.1)^{\star}$ & $1.3(0.8-2.2)$ \\
\hline MDE & $1.1(0.8-1.6)$ & $1.2(0.8-1.8)$ \\
\hline ODD & $0.9(0.5-1.7)$ & $1.4(0.8-2.3)$ \\
\hline Panic disorder & $0.8(0.5-1.2)$ & $1.1(0.6-2.2)$ \\
\hline PTSD & $1.1(0.6-1.8)$ & $1.1(0.6-2.2)$ \\
\hline SAD/ASA & $0.9(0.6-1.4)$ & $1.2(0.7-2.0)$ \\
\hline Social phobia & $1.1(0.7-1.6)$ & $0.6(0.4-1.0)$ \\
\hline Specific phobia & $1.0(0.7-1.5)$ & $1.1(0.7-1.6)$ \\
\hline
\end{tabular}

ADHD, attention-deficit hyperactivity disorder; $A S A$, adult separation anxiety; GAD, generalised anxiety disorder; IED, intermittent explosive disorder; MDE, major depressive episode; ODD, oppositional defiant disorder; PTSD, post-traumatic stress disorder; SAD, separation anxiety disorder.

${ }^{*} P<0.05$ 


\begin{tabular}{|c|c|c|c|c|c|c|c|c|}
\hline & \multicolumn{4}{|c|}{ Women } & \multicolumn{4}{|c|}{ Men } \\
\hline & \multirow[b]{2}{*}{ OR $(95 \% \mathrm{Cl})$} & \multicolumn{3}{|c|}{ Test for joint significance of both disorder variables } & \multirow[b]{2}{*}{ OR $(95 \% \mathrm{Cl})$} & \multicolumn{3}{|c|}{ Test for joint significance of both disorder variables } \\
\hline & & Wald $\chi^{2}$ & d.f. & $P$ & & Wald $\chi^{2}$ & d.f. & $P$ \\
\hline \multicolumn{9}{|l|}{ Any marital violence } \\
\hline Any disorder & & 3.2 & 2 & 0.1989 & & 12.3 & 2 & 0.0021 \\
\hline Any externalising & $1.2(0.9-1.7)$ & & & & $1.7(1.2-2.3)^{\star}$ & & & \\
\hline Any internalising & $1.2(0.9-1.6)$ & & & & $1.1(0.8-1.5)$ & & & \\
\hline \multicolumn{9}{|l|}{$\begin{array}{l}\text { Both perpetrator } \\
\text { and victim }\end{array}$} \\
\hline Any disorder & & 7.5 & 2 & 0.024 & & 6.9 & 2 & 0.0313 \\
\hline Any externalising & $1.4(0.8-2.2)$ & & & & $1.9(1.2-3.1)^{*}$ & & & \\
\hline Any internalising & $1.6(1.0-2.4)^{*}$ & & & & $1.2(0.8-1.9)$ & & & \\
\hline \multicolumn{9}{|l|}{ Perpetrator only } \\
\hline Any disorder & & 3.1 & 2 & 0.2098 & & 14.6 & 2 & 0.0007 \\
\hline Any externalising & $1.2(0.7-2.2)$ & & & & $2.2(1.4-3.5)^{*}$ & & & \\
\hline Any internalising & $0.6(0.3-1.1)$ & & & & $1.1(0.7-1.9)$ & & & \\
\hline \multicolumn{9}{|l|}{ Victim only } \\
\hline Any disorder & & 2.7 & 2 & 0.2564 & & 0.8 & 2 & 0.6604 \\
\hline Any externalising & $0.8(0.4-1.6)$ & & & & $1.0(0.5-2.0)$ & & & \\
\hline Any internalising & $1.4(0.9-2.0)$ & & & & $0.8(0.5-1.3)$ & & & \\
\hline
\end{tabular}

with externalising disorders more likely to be married to men with externalising disorders $(\mathrm{OR}=2.2,95 \% \mathrm{CI}$ 1.4-3.4) (full results available from the authors on request).

\section{Premarital mental disorders and marital violence}

To account for the potential confounding by marital selection, associations between premarital mental disorders and marital violence were examined in a data-set in which each couple was represented by a single observation. Premarital externalising and internalising disorders in each spouse were examined as predictors of any marital violence, with statistical adjustment for age at start of marriage (both husband's and wife's), years in the marriage, husband's and wife's education, and country (Table 5). All four odds ratios were greater than 1, indicating a higher risk of marital violence among couples with any disorder, but only one - that for husband's externalising disorders - reached statistical significance. To test whether specific combinations of spousal premarital disorders were associated with risk of marital violence over and above the associations shown in Table 5, a series of models with statistical interactions between husband and wife disorders were specified. Fit indices showed that none of the interaction models was superior to the main effects model. The latter model was used to estimate population attributable risk proportions of marital violence associated with mental disorders (Table 5). Across all 11 countries, $17.2 \%$ of cases of marital violence were attributable to premarital mental disorders, with men's externalising disorders accounting for over half of that proportion (9.5\%). Mental disorders accounted for similar proportions of marital violence in high/middle- and low-income countries $(17.4 \%$ and $15.4 \%$ respectively).

\section{Cross-national variations}

Statistical interactions between mental disorders and country income level in the prediction of physical violence in marital relationships were tested to examine whether the associations observed in the pooled data-set differed systematically across countries. The global test for all eight interactions (four measures of mental disorders crossed with two dummy variables for country income level) between mental disorders and the outcome was not significant $\left(\chi^{2}(8)=8.5, P=0.38\right)$. Furthermore, three of the four interactions of individual mental disorder measures with country income level were insignificant $\left(\chi^{2}=0.92-0.24, P=0.63-0.89\right)$. The remaining interaction, husbands' internalising disorders with country income level, was significant $\left(\chi^{2}=7.0, P=0.031\right)$, with the odds ratios associated with husbands' internalising disorders being 1.0 (95\% CI 0.7-1.4) in high-income countries, 2.1 (95\% CI 1.3-3.6) in middleincome countries and 1.5 (95\% CI 0.9-2.7) in low-income countries. However, the insignificant global test suggests that this one significant component test could have occurred by chance.

\section{Discussion}

Results of this study should be interpreted in the light of several limitations, including the reliance on retrospective self-reports.

Table 5 Multivariate models predicting any violence in the couples sample

\begin{tabular}{|c|c|c|c|c|}
\hline \multirow[b]{2}{*}{ Premarital mental disorder } & \multirow[b]{2}{*}{ OR $(95 \% \mathrm{Cl})^{\mathrm{a}}$} & \multicolumn{3}{|c|}{ Population attributable risk } \\
\hline & & High/middle-income countries, \% & Low-income countries, \% & All countries, $\%$ \\
\hline All disorders & & 17.40 & 15.40 & 17.20 \\
\hline Husband's externalising & $1.7(1.3-2.1)^{\star}$ & 9.20 & 7.80 & 9.50 \\
\hline Wife's externalising & $1.3(0.9-1.7)$ & 3.30 & 0.30 & 2.00 \\
\hline Husband's internalising & $1.1(0.9-1.4)$ & 0.70 & 4.00 & 1.60 \\
\hline Wife's internalising & $1.2(1-1.6)$ & 4.80 & 3.70 & 4.80 \\
\hline
\end{tabular}


Respondents may have forgotten events or made errors in the timing of events. Inaccuracies are especially likely in reported ages at onset of psychiatric disorder. ${ }^{19}$ The distributions of age at onset reported in other studies using these data are consistent with distributions found in prospective studies, ${ }^{20,21}$ suggesting that recall bias might not have had a significant role in this regard. Moreover, systematic reviews on the use of retrospective surveys have revealed that despite the limitations mentioned above, participants in retrospective studies are able to recall experiences from as far back as childhood and adolescence with sufficient precision to provide accurate and useful information. ${ }^{22,23}$ In addition, the survey was structured to assist respondents in recalling age at onset using the timing of other significant events in their lives. A second significant limitation is that the assessment of violence in this survey focused solely on physical violence, and did not include sexual violence or emotional abuse, and thus does not provide a comprehensive assessment of intimate partner violence. Future studies should investigate whether the patterns identified here apply to other forms of intimate partner violence. Third, epidemiological surveys have limited capacity to differentiate between physical violence victimisation and perpetration; most respondents report both, and perpetration is likely to be underreported. ${ }^{24}$ The analyses thus focused on 'any marital violence' as reported by either spouse, which may better reflect the risk of being in a marital or marriage-like relationship in which physical violence occurs. Fourth, the survey did not include length of time in the relationship prior to marriage (95\% of the couples were married), which may have resulted in overcounting premarital onset of mental disorders (some disorders might have actually started after the start of the current relationship but prior to actual marriage). Fifth, data collection on a limited number of childhood disorders was limited to participants aged 18-44 years, which does introduce a bias. Since this was done systematically across surveys by design, missing values on these disorders for the older age cohorts only introduce a small bias owing to the absence of an adult ADHD measure. Comparison of results in the 44 years and under age range with those in the over- 44 group suggested that such bias was small. Finally, the presence of the spouse in the room during the interview may also have contributed to underreporting of marital violence. As noted earlier in the description of survey methods, every effort was made to ensure private responses to the violence-related questions through use of a respondent booklet rather than reading out the list of violent behaviours to the respondent. In countries such as India where the percentage of spouses present during interview was high, the reporting of marital violence was still substantial, although likely to be an underestimate.

These limitations notwithstanding, this study has four notable strengths. First, the sample comprised population samples from a diverse set of countries assessed for marital violence and mental disorders with the same survey instrument. This cross-national study expands the scope of previous research on mental health and marital violence, which has been largely confined to high-income Western countries. Second, this representative sample offers the opportunity to calculate population attributable risk proportions to estimate the contribution of premarital mental disorders to risk of physical violence in marriage. Third, only premarital disorders were examined as predictors of marital violence, excluding disorders that might have occurred later as a result of violence during the marriage. Finally, data on both members of married couples allowed for combination of spousal reports in the assessment of marital violence and statistical adjustment for spousal mental disorders.

\section{Discordance in reporting}

Discordance between spouses in reporting marital violence was substantial. In three-quarters of the couples in which one member reported physical violence, reports were discordant on either the presence of any violence at all or the role of each spouse in the violence. Combining reports of both spouses raised the estimated prevalence of marital violence in the sample by more than $50 \%$, from $13.1 \%$ to $20 \%$. Although the higher estimate derived from combining reports of both spouses is probably closer to the true prevalence of marital violence, it is likely that it remains an underestimate for three reasons. First, both members of couples, including victims, might have reasons to avoid disclosure of violence in the relationship because of social undesirability. ${ }^{25}$ Second, the marital violence measure was limited to acts of physical violence, and did not include sexual violence or emotional abuse. Third, since the sample was representative of current marriages, marriages of short duration were underrepresented. If marital violence is associated with divorce, then the sample of current marriages is likely to have proportionally fewer marriages with marital violence. Fourth, the presence of a spouse or family member in some of the interviews might also contribute to underreporting. The predictors for discordance in reporting of violence including demographic characteristics, history of mental disorder and presence of spouse during interview merit further study.

Having the mental health histories of both spouses enabled us to examine the possibility of confounding by marital selection through statistical adjustment for spousal premarital mental disorders. $^{26,27}$ This approach distinguished between the wife's and the husband's mental health histories in predicting marital violence, and highlighted an important gender difference in the contribution of premarital mental disorders to marital violence. Analysis of the couples data suggests that the primary contribution of premarital mental disorders to physical violence in marriage is through the husband's externalising disorders. It has also been suggested that the impact of mental disorders on violence in one partner might depend on mental disorders in the other partner. For instance, people with externalising disorders might be at higher risk if married to a partner with an externalising disorder rather than a partner with no disorder or an internalising disorder. $^{28}$ Marriages between men with externalising disorders and women with internalising disorders may be at particularly high risk of marital violence. ${ }^{29}$ If either of these hypothetical synergies between disorders were true, we should expect to find statistical interactions between disorders in spouses, which we did not. This suggests that the influence of male externalising disorder on risk of marital violence is of similar magnitude regardless of the history of mental health problems in the spouse.

\section{Pathways to violence}

One potential pathway connecting externalising disorders and marital violence is suggested by research on family violence and the intergenerational continuity of violence. Childhood exposure to family violence (including childhood physical and sexual abuse as well as exposure to interparental violence) is associated with violence in adult relationships, ${ }^{30-32}$ and childhood exposure to family violence is associated with increased risk of early onset of mental disorders. ${ }^{1,30,33-38}$ It is important to note, however, that associations of childhood adverse experiences with adolescent and adult mental disorders are not specific to externalising disorders. Internalising disorders in women make a much smaller contribution to the risk of marital violence. Although the association with wife's internalising disorders remains in the 
couples sample, this is barely significant and not large (the population attributable risk proportion is smaller than that for male externalising disorders, $4.8 \%$ compared with 9.5\%). Calculation of population attributable risk involves simulations that assume that the model represents causal relationships, and thus must be interpreted cautiously as a gross estimate of attributable risk. The apparent variations in population attributable risk proportions suggest that the mechanisms underlying how premarital mental disorders contribute to marital violence vary by type of disorder and gender, and that targeted interventions should be investigated.

Although some of the externalising disorders do include history of fighting as part of the determination for presence of the disorder (i.e. aggressive behaviour such as occurs with conduct or oppositional defiant disorder), in the disorder-specific analyses (Table 3) the associations of conduct and oppositional defiant disorder with marital violence were not statistically significant. The relationship between early-onset disruptive, impulsive and/ or aggressive behaviours associated with externalising disorders and any marital violence may reflect the known co-occurrence of multiple forms of violence victimisation and perpetration among individuals. Studies have also suggested that the contribution of mental disorders to violent behaviour in general is not as strong as previously assumed. ${ }^{39}$

\section{Violence reduction strategies}

The association between externalising disorders and marital violence suggests that early identification and treatment of externalising disorders among males in school, clinical and community-based settings might be an important strategy to reduce risk of subsequent marital violence. Second, a related strategy for reducing risk of marital violence might involve working with alcohol treatment programmes to engage their clients in skills building and counselling to address and reduce violence in their relationships. It is important to note in this regard that although there was no apparent distinction between the impact of substance use disorders and that of other externalising disorders (e.g. conduct disorder) on marital violence once adjustments for co-occurrence were included, these conditions are behaviourally quite distinct and may require tailored treatment approaches. Identification and treatment of internalising disorders, although important, is less likely to result in significant reductions in marital violence.

\section{Implications of the study}

These findings point to a modest but consistent contribution of mental disorders to risk of marital violence across diverse countries, even after accounting for variation in prevalence of both mental disorders and marital violence, with three key implications. First, some cases of physical violence in marital relationships appear to be related to premarital mental disorders; thus identification of and intervention with men with externalising disorders, in particular in adolescence and early adulthood, may be one strategy for preventing at least some marital violence. Second, the consistency of the attributable risk for any marital violence that is associated with husbands' externalising disorders across these varied national settings suggests that, at least for this subset of disorders, there is likely to be a common pathway whereby early disruptive and impulsive behaviour patterns continue into adult intimate relationships. However, the third implication of these findings for violence prevention is that the contribution of premarital mental disorders to risk of marital violence is modest, suggesting that a number of other factors contribute to the complex aetiology of violence in intimate relationships, including unequal power dynamics, gender inequity and social norms regarding violence within relationships. Based on these findings, targeted mental health interventions for individuals at risk of physical violence in their intimate relationships should be considered one strategy among many for the prevention of marital violence, which affects large numbers of men and women around the globe.

In summary, husbands' externalising disorders appear to be the primary mental health component contributing to risk of marital violence across both lower- and higher-income countries after accounting for other mental disorders and marital selection. This finding has implications for the development of targeted interventions to reduce risk of marital violence. Premarital mental disorders appear to be less predictive of marital violence risk for women compared with men. The mechanisms through which male externalising disorders may increase risk of marital violence and explanations for the gender difference merit further study. Although these findings do support exploring the role of early mental health interventions in addressing subsequent risk of physical violence in marital relationships, the overall global impact on marital violence prevention may be limited.

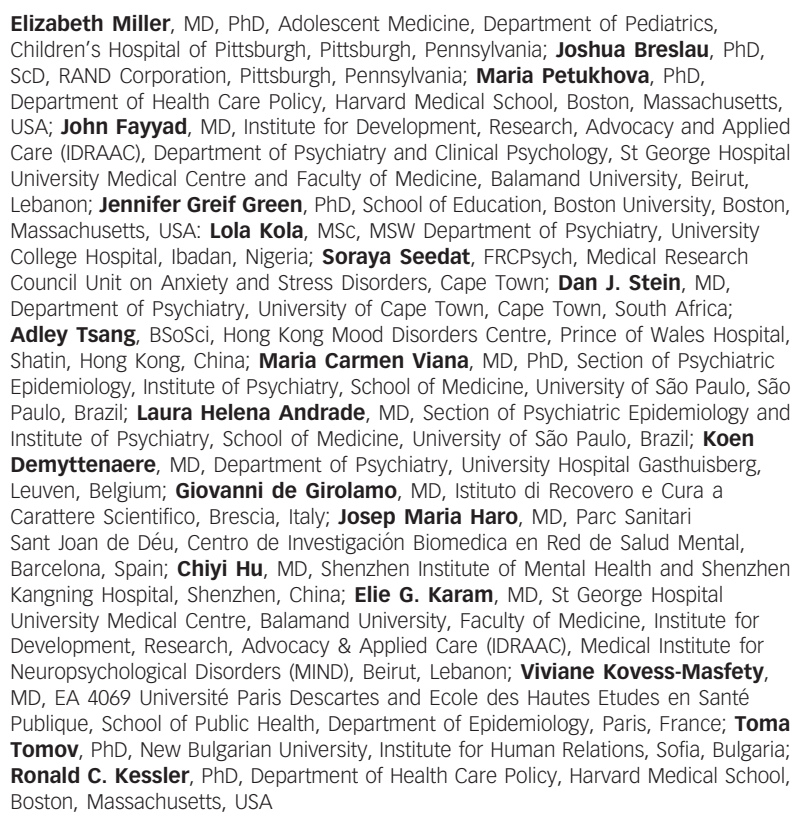

Elizabeth Miller, MD, PhD, Adolescent Medicine, Department of Pediatrics, Children's Hospital of Pittsburgh, Pittsburgh, Pennsylvania; Joshua Breslau, PhD, $\mathrm{SCD}$, RAND Corporation, Pittsburgh, Pennsylvania; Maria Petukhova, PhD, Department of Health Care Policy, Harvard Medical School, Boston, Massachusetts, USA; John Fayyad, MD, Institute for Development, Research, Advocacy and Applied Care (IDRAAC), Department of Psychiatry and Clinical Psychology, St George Hospital University Medical Centre and Faculty of Medicine, Balamand University, Beirut, Lebanon; Jennifer Greif Green, PhD, School of Education, Boston University, Boston, Massachusetts, USA: Lola Kola, MSc, MSW Department of Psychiatry, University College Hospital, Ibadan, Nigeria; Soraya Seedat, FRCPsych, Medical Research Council Unit on Anxiety and Stress Disorders, Cape Town; Dan J. Stein, MD, Department of Psychiatry, University of Cape Town, Cape Town, South Africa; Adley Tsang, BSoSci, Hong Kong Mood Disorders Centre, Prince of Wales Hospital, Shatin, Hong Kong, China; Maria Carmen Viana, MD, PhD, Section of Psychiatric Epidemiology, Institute of Psychiatry, School of Medicine, University of São Paulo, são Paulo, Brazil; Laura Helena Andrade, MD, Section of Psychiatric Epidemiology and Institute of Psychiatry, School of Medicine, University of São Paulo, Brazil; Koen Demyttenaere, MD, Department of Psychiatry, University Hospital Gasthuisberg, Leuven, Belgium; Giovanni de Girolamo, MD, Istituto di Recovero e Cura a Carattere Scientifico, Brescia, Italy; Josep Maria Haro, MD, Parc Sanitari Sant Joan de Déu, Centro de Investigación Biomedica en Red de Salud Mental, Barcelona, Spain; Chiyi Hu, MD, Shenzhen Institute of Mental Health and Shenzhen Kangning Hospital, Shenzhen, China; Elie G. Karam, MD, St George Hospital University Medical Centre, Balamand University, Faculty of Medicine, Institute for Development, Research, Advocacy \& Applied Care (IDRAAC), Medical Institute for Neuropsychological Disorders (MIND), Beirut, Lebanon; Viviane Kovess-Masfety, MD, EA 4069 Université Paris Descartes and Ecole des Hautes Etudes en Santé Publique, School of Public Health, Department of Epidemiology, Paris, France; Toma Tomov, PhD, New Bulgarian University, Institute for Human Relations, Sofia, Bulgaria; Ronald C. Kessler, PhD, Department of Health Care Policy, Harvard Medical School, Boston, Massachusetts, USA

Correspondence: Dr Elizabeth Miller, Davis School of Medicine, Room 382,Ticon II Building, 2516 Stockton Boulevard, Sacramento, California 95817, USA. Email: elizabeth.miller@ucdmc.ucdavis.edu

First received 9 Jul 2010, final revision 10 Mar 2011, accepted 24 Apr 2011

\section{Funding}

The World Health Organization (WHO) World Mental Health (WMH) Survey Initiative is supported by the National Institute of Mental Health (R01 MH070884), the John D. and Catherine T. MacArthur Foundation, the Pfizer Foundation, the US Public Health Service (R13-MH066849, R01-MH069864 and R01 DA016558), the Mental Health Burden Study (contract number HHSN271200700030C), the Fogarty International Center (FIRCA R03TW006481), the Pan American Health Organization, Eli Lilly, Ortho-McNeil Pharmaceutical, GlaxoSmithKline, Bristol-Myers Squibb and Shire Pharmaceuticals. The work of L.D., H.C. and J.C.A. in preparing this report was additionally supported by the National Institute on Drug Abuse (K05DA015799; R01DA016558) and the work of L.D. was funded by an Australian National Health and Medical Research Council senior research fellowship. The São Paulo Megacity Mental Health Survey is supported by the State of São Paulo Research Foundation (FAPESP Thematic Project Grant 03/00204-3). The Bulgarian Epidemiological Study of Common Mental Disorders is supported by the Ministry of Health and the National Centre for Public Health Protection. The Shenzhen Mental Health Survey is supported by the Shenzhen Bureau of Health and the Shenzhen Bureau of Science, Technology and the Shenzhen Bureau of Health and the Shenzhen Bureau of Science, Technology and
Information. The European Study of the Epidemiology of Mental Disorders (ESEMeD) is funded by the European Commission (contracts QLG5-1999-01042; SANCO 2004123), the 
Piedmont Region, Italy, Fondo de Investigación Sanitaria, Instituto de Salud Carlos III, Spain (FIS 00/0028), Ministerio de Ciencia y Tecnología, Spain (SAF 2000-158-CE), Departament de Salut, Generalitat de Catalunya, Spain, Instituto de Salud Carlos III (CIBER CB06/02/0046, RETICS RD06/0011 REM-TAP), and other local agencies and by an unrestricted educational grant from GlaxoSmithkline. The Epidemiological Study on Mental Disorders in India was funded jointly by the Government of India and WHO. The Lebanese National Mental Health funded jointly by the Government of India and WHO. The Lebanese National Mental Health
survey (LEBANON) is supported by the Lebanese Ministry of Public Health, the WHO Survey (LEBANON) is supported by the Lebanese Ministry of Public Health, the WHO
(Lebanon), Fogarty International, anonymous private donations to the Institute fo Development, Research, Advocacy and Applied Care, Lebanon, and unrestricted grants from Janssen Cilag, Eli Lilly, GlaxoSmithKline, Roche and Novartis. The Nigerian Survey of Mental Health and Wellbeing is supported by the WHO (Geneva and Nigeria) and by the Federal Ministry of Heath, Abuja, Nigeria The US Nationat Comorbidity Survey Replication is supported by the Nation A I stigeria. Men support from the National Institute of Drug Abuse, the Substance Abuse and Mental Health Services Administration, the Robert Wood Johnson Foundation (grant 044708) and the John W. Alden Trust.

\section{Acknowledgements}

This report was prepared as part of the World Health Organization World Mental Health (WMH) Survey Initiative. We thank the staff of the WMH data collection and data analysis coordination centres for assistance with instrumentation, fieldwork and consultation on data analysis.

\section{References}

1 Stith SM, Smith DB, Penn CE, Ward DB, Tritt D. Intimate partner physical abuse perpetration and victimization risk factors: a meta-analytic review. Aggress Violent Behav 2004; 10: 65-98.

2 Afifi TO, MacMillan H, Cox BJ, Asmundson GJG, Stein MB, Sareen J. Mental health correlates of intimate partner violence in marital relationships in a nationally representative sample of males and females. $J$ Interpers violence 2009: 24: 1398-417.

3 Kim HK, Laurent HK, Capaldi DM, Feingold A. Men's aggression toward women: a 10-year panel study. J Marriage Fam 2008; 70: 1169-87.

4 Renner LM. Intimate partner violence victimization and parenting stress: assessing the mediating role of depressive symptoms. Violence against Women 2009; 15: 1380-401.

5 Kessler RC, Molnar BE, Feurer ID, Appelbaum M. Patterns and mental health predictors of domestic violence in the United States: results from the National Comorbidity Survey. Int J Law Psychiatry 2001; 24: 487-508.

6 Lorber MF, O'Leary KD. Predictors of the persistence of male aggression in early marriage. J Fam Violence 2004; 19: 329-38.

7 Riggs DS, Caulfield MB, Street AE. Risk for domestic violence: factors associated with perpetration and victimization. J Clin Psychol 2000; 56 1289-316.

8 Fergusson DM, John Horwood L, Ridder EM. Show me the child at seven: the consequences of conduct problems in childhood for psychosocial functioning in adulthood. J Child Psychol Psych 2005; 46: 837-49.

9 Fang XM, Massetti GM, Ouyang LJ, Grosse SD, Mercy JA. Attention-deficit/ hyperactivity disorder, conduct disorder, and young adult intimate partner violence. Arch Gen Psychiatry 2010; 67: 1179-86.

10 Lehrer JA, Buka S, Gortmaker S, Shrier LA. Depressive symptomatology as a predictor of exposure to intimate partner violence among US female adolescents and young adults. Arch Pediatr Adolesc Med 2006; 160: 270-6.

11 The World Bank. Data. The World Bank, 2011 (http://data.worldbank.org/ country).

12 Pennell BE, Mneimneh Z, Bowers A, Chardoul S, Wells JE, Viana MC, et al. Implementation of the World Mental Health Surveys. In The WHO World Mental Health Surveys: Global Perspectives on the Epidemiology of Mental Disorders (eds R Kessler, T Üstün): 33-57. Cambridge University Press, 2008.

13 Kessler R, Ustün T. The World Mental Health (WMH) Survey Initiative Version of the World Health Organization (WHO) Composite International Diagnostic Interview (CIDI). Int J Methods Psychiatr Res 2004; 13: 93-121.

14 Harkness J, Pennell B, Villar A, Gebler N, Aguilar-Gaxiola S, Bilgen I. Translation procedures and translation assessment in the World Mental Health Survey Initiative. In The WHO World Mental Health Surveys: Global Perspectives on the Epidemiology of Mental Disorders (eds R Kessler, T Üstün): 91-113. Cambridge University Press, 2008.

15 Kessler RC, Abelson J, Demler O, Escobar Jl, Gibbon M, Guyer ME, et al. Clinical calibration of DSM-IV diagnoses in the World Mental Health (WMH) version of the World Health Organization (WHO) Composite International Diagnostic Interview (WMH-CIDI). Int J Methods Psychiatr Res 2004; 13: 122-39.
16 First MB, Spitzer RL, Gibbon M, Williams JBW. Structured Clinical Interview for DSM-IV Axis I Disorders, Research Version, Non-patient Edition (SCID-I/NP). Biometrics Research, New York State Psychiatric Institute, 2002.

17 Haro JM, Arbabzadeh-Bouchez S, Brugha TS, De Girolamo G, Guyer ME, Jin R, et al. Concordance of the composite international diagnostic interview version 3.0 (CIDI 3.0) with standardized clinical assessments in the WHO World Mental Health Surveys. Int J Methods Psychiatr Res 2006; 15: 167-80.

18 Straus MA, Hamby SL, Boney-McCoy S, Sugarman DB. The Revised Conflict Tactics Scales (CTS2). J Fam Issues 1996; 17: 283-316.

19 Kazemian L, Farrington DP. Comparing the validity of prospective, retrospective, and official onset for different offending categories. J Quant Criminol 2005; 21: 127-47.

20 Lahey B, Miller T, Gordon R, Riley A. Developmental epidemiology of the disruptive behavior disorders. In Handbook of the Disruptive Behavior Disorders (eds H Quay, A Hogan): 23-48. Plenum, 1999.

21 Maughan B, Rowe R, Messer J, Goodman R, Meltzer H. Conduct disorder and oppositional defiant disorder in a national sample: developmental epidemiology. J Child Psychol Psychiatry 2004; 45: 609-21.

22 Brewin CR, Andrews B, Gotlib IH. Psychopathology and early experience: a reappraisal of retrospective reports. Psychol Bull 1993; 113: 82-98.

23 Hardt J, Rutter M. Validity of adult retrospective reports of adverse childhood experiences: review of the evidence. J Child Psychol Psychiatry 2004; 45 260-73.

24 Hamby SL. Measuring gender differences in partner violence: implications from research on other forms of violent and socially undesirable behavior. Sex Roles 2005; 52: 725-42.

25 Ellsberg M, Heise L, Pena R, Agurto S, Winkvist A. Researching domestic violence against women: methodological and ethical considerations. Stud Fam Plann 2001; 32: 1-16.

26 Krueger RF, Moffitt TE, Caspi A, Bleske A, Silva PA. Assortative mating for antisocial behavior: developmental and methodological implications. Behav Genet 1998; 28: 173-86.

27 Maes H, Neale M, Kendler K, Hewitt J, Silberg J, Foley D, et al. Assortative mating for major psychiatric diagnoses in two population-based samples. Psychol Med 1998; 28: 1389-401.

28 Ehrensaft MK. Intimate partner violence: persistence of myths and implications for intervention. Child Youth Serv Rev 2008; 30: 276-86.

$29 \mathrm{Kim} \mathrm{HK}$, Capaldi DM. The association of antisocial behavior and depressive symptoms between partners and risk for aggression in romantic relationships. J Fam Psychol 2004; 18: 82-96.

30 Ehrensaft MK, Cohen P, Brown J, Smailes E, Chen HN, Johnson JG. Intergenerational transmission of partner violence: a 20 -year prospective study. J Consult Clin Psychol 2003; 71: 741-53.

31 Gil-Gonzalez D, Vives-Cases C, Ruiz MT, Carrasco-Portino M, Alvarez-Dardet C. Childhood experiences of violence in perpetrators as a risk factor of intimate partner violence: a systematic review. J Public Health 2008; 30: 14-22.

32 Herrenkohl T, Mason W, Kosterman R, Lengua L, Hawkins J, Abbott R. Pathways from physical childhood abuse to partner violence in young adulthood. Violence vict 2004; 19: 123-36.

33 Afifi TO, Enns MW, Cox BJ, Asmundson GJG, Stein MB, Sareen J. Population attributable fractions of psychiatric disorders and suicide ideation and attempts associated with adverse childhood experiences. Am J Public Health 2008; 98: 946-52.

34 Dube SR, Anda RF, Felitti VJ, Chapman DP, Williamson DF, Giles WH Childhood abuse, household dysfunction, and the risk of attempted suicide throughout the life span - findings from the adverse childhood experiences study. JAMA 2001; 286: 3089-96.

35 Green JG, McLaughlin KA, Berglund PA, Gruber MJ, Sampson NA, Zaslavsky $\mathrm{AM}$, et al. Childhood adversities and adult psychiatric disorders in the national comorbidity survey replication I: associations with first onset of DSM-IV disorders. Arch Gen Psychiatry 2010; 67: 113-23.

36 Kessler RC, Davis CG, Kendler KS. Childhood adversity and adult psychiatric disorder in the US National Comorbidity Survey. Psychol Med 1997; 27: 1101-19.

37 Levendosky AA, Huth-Bocks A, Semel MA. Adolescent peer relationships and mental health functioning in families with domestic violence. J Clin Child Adolesc Psychol 2002; 31: 206-18.

38 McLaughlin KA, Green JG, Gruber MJ, Sampson NA, Zaslavsky AM, Kessler RC. Childhood adversities and adult psychiatric disorders in the national comorbidity survey replication II: associations with persistence of DSM-IV disorders. Arch Gen Psychiatry 2010; 67: 124-32.

39 Elbogen EB, Johnson SC. The intricate link between violence and mental disorder. Arch Gen Psychiatry 2009; 66: 152-61. 